\title{
Genetic polymorphism of histidine rich protein 2 in Plasmodium falciparum isolates from different infection sources in Yunnan Province, China
}

\author{
Ying Dong ${ }^{*^{*}}\left(\mathbb{D}\right.$, Shuping $\mathrm{Liu}^{1,2}$, Yan Deng ${ }^{1}$, Yanchun $\mathrm{Xu}^{1}$, Mengni Chen ${ }^{1}$, Yan Liu ${ }^{1}$ and Jingpo Xue
}

\begin{abstract}
Background: Failed diagnoses of some falciparum malaria cases by RDTs are constantly reported in recent years. Plasmodium falciparum histidine-rich protein 2 (pfhpr2) gene deficiency has been found to be the major reason of RDTs failure in many countries. This article analysed the deletion of pfhpr2 gene of falciparum malaria cases isolated in Yunnan Province, China.

Methods: Blood samples from falciparum malaria cases diagnosed in Yunnan Province were collected. Plasmodium genomic DNA was extracted and the pfhrp2 gene exon2 region was amplified via nested PCR. The haplotype of the DNA sequence, the nucleic acid diversity index (PI) and expected heterozygosity (He) were analyzed. Count PfHRP2 amino acid peptide sequence repeat and its times, and predict the properties of PfHRP2 peptide chain reaction to RDTs testing.
\end{abstract}

Results: A total of 306 blood samples were collected, 84.9\% (259/306) from which pfhrp2 PCR amplification products (gene exon2) were obtained, while the remaining 47 samples were false amplification. The length of the 250 DNA sequences ranged from 345 - 927 bp, with 151 haplotypes, with PI and He values of 0.169 and 0.983, respectively. The length of the PAHRP2 peptide chain translated from 250 DNA sequences ranged from 115 to 309 aa. All peptide chains had more than an amino acid codon deletion. All 250 PfHRP2 strands ended with a type 12 amino acid repeat, $98.0 \%$ (245/250) started with a type 1 repetition and 2.0\% (5/250) with a type 2 repetition. The detection rate for type 2 duplicates was 100\% (250/250). Prediction of RDT sensitivity of PfHRP2 peptide chains based on type 2 and type 7 repeats showed that $9.60 \%$ (24/250), 50.0\% (125/250), 13.20\% (33/250) and 27.20.5\% (68/250) of the 250 peptide chains were very sensitive, sensitive, borderline and non-sensitive, respectively.

Conclusion: The diversified polymorphism of the pfhrp2 gene deletion from different infection sources in the Yunnan province are extremely complex. The cause of the failure of pfhrp2 exon2 amplification is still to be investigated. The results of this study appeal to Yunnan Province for a timely evaluation of the effectiveness and applicability of RDTs in the diagnosis of malaria.

Keywords: Yunnan, Different infection sources, Plasmodium falciparum, Histidine-rich protein 2, Peptid chain, Deletion polymorphism

\footnotetext{
*Correspondence: luxidongying@126.com

${ }^{1}$ Yunnan Institute of Parasitic Diseases Control, Yunnan Provincial Key

Laboratory, Yunnan Centre of Malaria Research, Academician Workstation of Professor Jin Ningyi, Pu'er 665000, China

Full list of author information is available at the end of the article
}

\section{Background}

Yunnan was one of the only two provinces in China where malaria was indigenous endemic cases as of 2013 [1,2]. The number of malaria cases diagnosed by parasitology

(c) The Author(s) 2019. This article is licensed under a Creative Commons Attribution 4.0 International License, which permits use, sharing, adaptation, distribution and reproduction in any medium or format, as long as you give appropriate credit to the original author(s) and the source, provide a link to the Creative Commons licence, and indicate if changes were made. The images or other third party material in this article are included in the article's Creative Commons licence, unless indicated otherwise in a credit line to the material. If material is not included in the article's Creative Commons licence and your intended use is not permitted by statutory regulation or exceeds the permitted use, you will need to obtain permission directly from the copyright holder. To view a copy of this licence, visit http://creativecommons.org/licenses/by/4.0/. The Creative Commons Public Domain Dedication waiver (http://creativecommons.org/publicdomain/zero/1.0/) applies to the data made available in this article, unless otherwise stated in a credit line to the data. 
method (including microscopy and genetic test) in Yunnan Province took over 17.3\% (533/3078) of China, and $45.0 \%(9 / 20)$ of highly endemic counties in 2014 [2]. Although the number of reported malaria cases in the Yunnan Province has been the highest in China since 2016, but all the cases were imported [3]. Among them, Myanmar (Burma) was the largest source of imported malaria cases, taking over $84.9 \%$ (477/562), while falciparum malaria was the main type of imported malaria from Africa $(92.9 \%, 79 / 85)$. The patients were mainly farmers and businessmen who work abroad. Cases were found mainly in Tengchong, Ruili and Yinjiang counties along the China-Myanmar border. Therefore, Yunnan Province pays special attention to timely diagnosis and discovery of malaria spreading sources with measures such as vector control for stop malaria spreading and sensitivity monitoring for anti-malaria drugs [4-7]. A specific strategy, focused on the primary medical health institutions and individual clinics across the province, is to promote the use of immune rapid diagnostic tests (RDTs), such as Wonfo rapid diagnostic cassette which sensitivity was almost 95\% for Plasmodium falciparum in 2008 [8]. The use of RDTs are up to ten thousands cassettes per year in order to ensure that the malaria cases in the far rural of Yunnan Province get timely screening, but malaria diagnosis must be confirmed pass through various stages of county-level, prefecture-level, and province-level malaria diagnostic laboratory. The confirmation methods include further parasitological microscopy by professionals in combination with genetic testing, in order to reach an accurate diagnosis of malaria and a general quality evaluation of RDTs diagnosis [6, 7, 9]. After several years of observation in Yunnan Province, false negative and false positive malaria cases by RDTs diagnosis occurred frequently, compared with the gold standard microscopic examination method. A systematic evaluation of the accuracy of RDTs diagnosis of malaria in Yunnan Province showed that nearly half of the RDTs were insensitive to about $3-33 \%$ of $P$. falciparum infections despite the tendency to overestimate the sensitivity and specificity [10]. The World Health Organization (WHO), after six rounds of RDT quality assessments, pointed out that the P. falciparum histidine-rich protein 2 (PfHRP2) gene deletion may be the mainly biological factor accounting for failed diagnoses of falciparum malaria. Meanwhile, the WHO appeal to the regions with falciparum malaria epidemic worldwide for promptly clarification and validation of the PfHRP2 (genes) deletion as well as its influence on the accuracy of RDTs diagnosis of malaria [11].

The target proteins of malaria RDTs diagnosis mainly include PfHRP2, $P$. falciparum lactate dehydrogenase (pLDH) and P. falciparum aldolase (ALD). The first two are the detection targets of most malaria RDT products
$[10,12]$, and $P f H R P 2$ is a specific diagnosis target protein for falciparum malaria. Unfortunately, since the existence of $P$. falciparum strains with pfhrp 2 gene deletion was first reported in the 1980s [13-15], the phenomena of pfhrp 2 gene deletion has been found in Peru [16], Mali [17], India [18, 19], Philippines [20], Senegal [21], Brazil [22], Yemen [23], Honduras [24]. Amoah et al. found that in Ghana the false negative rate by RDTs diagnosis for falciparum malaria was $52 \%$, and the proportion of undetected $p f h r p 2$ gene was as high as $40 \%$. In contrast, in areas with a false negative rate of $2 \%$, only $22 \%$ of $p f h r p 2$ genes were undetected [25]; hence, Amoah et al. speculated that the spread of $P$. falciparum without the pfhrp2 gene had increased the incidence of errors in RDT diagnosis of falciparum malaria in Ghana. The studies conducted by Akinyi et al. and Wurtz et al. indicated these phenomena of a combination of RDT diagnosis failures for falciparum malaria, and the $p f h r p 2$ gene entire deletion in P. falciparum isolates from Peru and Senegal [16, 26]. In Yemen [23], Angola [21], and India [19], entire deletion rates of the $p f h r p 2$ gene exon2 regions reached $9.5 \%, 10 \%$, and $23 \%$, respectively, indicating that these countries may have a higher risk of misdiagnosis with the $p f h r p 2$ (gene)-deficient strains when using PfHRP2target protein RDTs for falciparum malaria diagnosis. In 2014, Yang et al. detected the polymorphisms of pfhrp 2 gene in 20 P. falciparum isolates collected from the China-Myanmar border [27]. In 2015, Dong et al. also found the possibility of partial and entire polymorphisms of pfhrp2 gene deletion in falciparum malaria case isolates from Yunnan Province [28]. Certainly, there are exceptions across the world, for example, Kenya has not yet found any entire deletion of $p f h r p 2$ gene in $P$. falciparum $[29,30]$. However, given that Yunnan Province has not explored the reasons for the failure of RDT diagnoses of falciparum malaria, the polymorphism associated with pfhrp 2 gene deletion and its changes need to be further verified. More importantly, in response to the WHO's appeal for the selection and improvement of RDTs, it is essential to understand the prevalence of pfhrp 2 gene deficiency, PfHRP2 protein deficiency, the extent of antigenic variation, and to provide evidence for Yunnan Province to improve the quality of falciparum malaria RDT diagnoses [11, 30]. This study aimed to systematically analyse the data from an ongoing molecular epidemiological investigation on $p f h r p 2$ gene deletion in Yunnan Province.

\section{Methods}

\section{Ethics statement}

The study was approved by Yunnan Institute of Parasitic Diseases and by the Ethical Committee. Genetic testing experiment, etc. were performed on stored blood 
samples obtained as part of routine diagnostic work-up from patients with fever suspected of malaria. Although the absence of risk and the anonymous data processing are ensured among the study, consent from potential malaria patients need to be obtained during collecting blood samples.

\section{Study subjects and blood samples}

Blood samples from falciparum malaria cases were continuously collected diagnosed and reported by Yunnan Province, and officially registered and approved by the "China Information System for Disease Control Prevention from January 2013 to December 2018. P. falciparum infection was parasitological confirmed by both microscopic examination [31] and genetic testing [32]. The filter paper blood samples were simultaneously used for polymorphic analysis of $p f h r p 2$ gene sources of falciparum malaria infection were confirmed by epidemiological investigation.

\section{Plasmodium DNA extraction and its normality verification} Three filter paper blood drops, each with a diameter of $5 \mathrm{~mm}$, was taken, and Plasmodium genomic DNA was extracted according to the instructions of QIAgen Mini Kit (DNA Mini Kit, QIAamp company, Germany), and extracted genomic DNA liquid stored at $-20^{\circ} \mathrm{C}$ for later use. The $p f c r t$ gene exon2 region was amplified to verify whether the DNA extraction of the Plasmodium genome was normal [7].

\section{Amplification of the exon2 region of pfhrp2 gene by nested PCR}

The GenBank (https://www.ncbi.nlm.nih.gov/gene/) reference sequence (ID: nc_004329.3) was used to design primers and reaction conditions for PCR amplification of pfhrp2 gene exon2 [18, 20,33]. The forward and reverse primers for the first round of PCR amplification were $5^{\prime}$-TATCCGCTGCCGTTTT- $3^{\prime}$ and $5^{\prime}$-CGC TATCCCATAAATTACAAAA- $3^{\prime}$, respectively, and the primers for the second round were $5^{\prime}$-TGTGTAGCA AAAATGCAAAAGG-3' and 5' ${ }^{\prime}$-TTAATGGCGTAG GCAATGTG-3', respectively, that amplified 1,374,236$1,375,059$ bp in chromosome 8 (GenBank accession number, NC_004329.3), which coding region was from 57 to 301 aa of $p f h r p 2$ gene exon 2 region, and the product size was expected to be about $824 \mathrm{bp}$. Both first and second PCR reactions contained $2.6 \mu \mathrm{L}$ DNA template, $14 \mu \mathrm{L}$ of $2 \times$ Taq PCR mixed system (containing Taq enzyme that was purchased from Qiagen Biotech (Shanghai), 0.7 $\mu \mathrm{L}$ each forward and reverse primers $(20 \mu \mathrm{mol} / \mathrm{L})$, and $\mathrm{ddH}_{2} \mathrm{O}$ for a volume of $25 \mu \mathrm{L}$. Both the conditions of first and second PCR reactions were as follows: $95^{\circ} \mathrm{C}$ for 5 min; 35 cycles of $95^{\circ} \mathrm{C}$ for $30 \mathrm{~s}, 55^{\circ} \mathrm{C}$ for $40 \mathrm{~s}$, and $72{ }^{\circ} \mathrm{C}$ for $90 \mathrm{~s}$; and $72{ }^{\circ} \mathrm{C}$ for $7 \mathrm{~min}$. The amplified product of the second PCR was detected by $1.5 \%$ agarose, observed via $1.5 \%$ agarose gel electrophoresis (agarose and DNA standards were procured from Takara Biomedical Technology (Dalian). Then the positive products were sent to Shanghai Meiji Biomedical Technology Co., Ltd. for sequencing using the dideoxy chain-termination method. Sequenced data were analysed using Chromas Pro 2.33 software.

\section{Analysis of pfhrp2 gene polymorphism and amino acid repeat sequence}

DNA sequences from PCR product sequencing were aligned with the reference sequence of $p f h r p$ gene exon2 region (GenBank accession number, PF3D7_08318000) using BLAST module of NCBI after splicing or transformation in the DNA Star Lasergene 7.1 software [33-36]. The sorted DNA sequences were converted to amino acid sequences using MEGA 5.04 software [33-36]. The DNA sequence of the $p f h r p 2$ gene exon 2 region was analysed by Arlequin 3.5.2.2 software, and the haplotypes, the nucleic acid diversity index (PI) and expected heterozygosity $(\mathrm{He})$ were calculated [33, 36]. Jalview 2.10 .5 was used to prepare the Principal Component Analysis scatter diagram of the haplotypes. The amino acid repeat types of the PfHRP2 peptide chain were counted, and the identification of the amino acid repeat types followed the principle of "long rather than short". Such as, the " AHHAHHAAD " amino acid sequence was identified only as a type 2 repeat, not as a linkage between type 4 (AHH) and type 7 (AHHAAD), and the "AHHAHHATD" amino acid sequence was identified only as a type 14 repeat, not as a linkage between type $4(\mathrm{AHH})$ and type 6 (AHHATD) $[16-18,20,30] . F$ test was performed on the amino acid residues and sequence repeats in $p f h r p 2$ gene exon2 region using the SPSS16.0 software, and the inspection level was 0.05 .

\section{Prediction of RDTs testing sensitivity via the PfHRP2 peptide chain}

The product of the number of PfHRP2 repeat types 2 and 7 (type $2 \times$ type 7 ) was used to distinguish the sensitivity of PfHRP2 peptide chain reaction to RDTs. Assay products with sensitivity responses $>100,50-100,43,44-49$ and 43 to the RDTs were classified as very sensitive (group A) and sensitive (group B), borderline (group I) and non-sensitive (group C) peptides, respectively [30]. The response of RDTs for the PfHRP2 peptide chain in geographical populations of $P$. falciparum was evaluated via the $T$ test using SPSS16.0 software, and the inspection level was 0.05 . Arc Gis10.1 was used to map the distribution of samples including normal sequencing $p f h r p 2$ gene exon2 and failed cases [36]. 


\section{Results}

\section{Sample source and nested PCR amplification}

A total of 306 blood samples were collected from falciparum malaria cases, $84.9 \%$ (259/306) from which the target pfhrp 2 gene exon2 region was amplified, with a fragment length of about 345 (not shown in electrophoresis)-927 bp. 47 blood samples was not amplified to cover the target $p f h r p 2$ gene exon 2 region because its $p f c r t$ gene exon2 fragment (150 bp) was amplified and identified as normal DNA extracted from the Plasmodium genome.
Two hundred and fifty-nine blood samples has been through the PCR amplification products of phhrp2 gene exon2 region, collected from prefecture falciparum malaria cases including Dehong (103 cases), Kunming (43 cases), Baoshan (41 cases), Dali (16 cases), Lincang (15 cases), Qujing (7 cases), Zhaotong (7 cases), Puer (7 cases), Wenshan (5 cases), Nujiang (4 cases), Xishuangbanna (4 cases), Lijiang (3 cases), Honghe (2 cases), Yuxi (1 case), Chuxiong (1 cases) (Fig. 1).

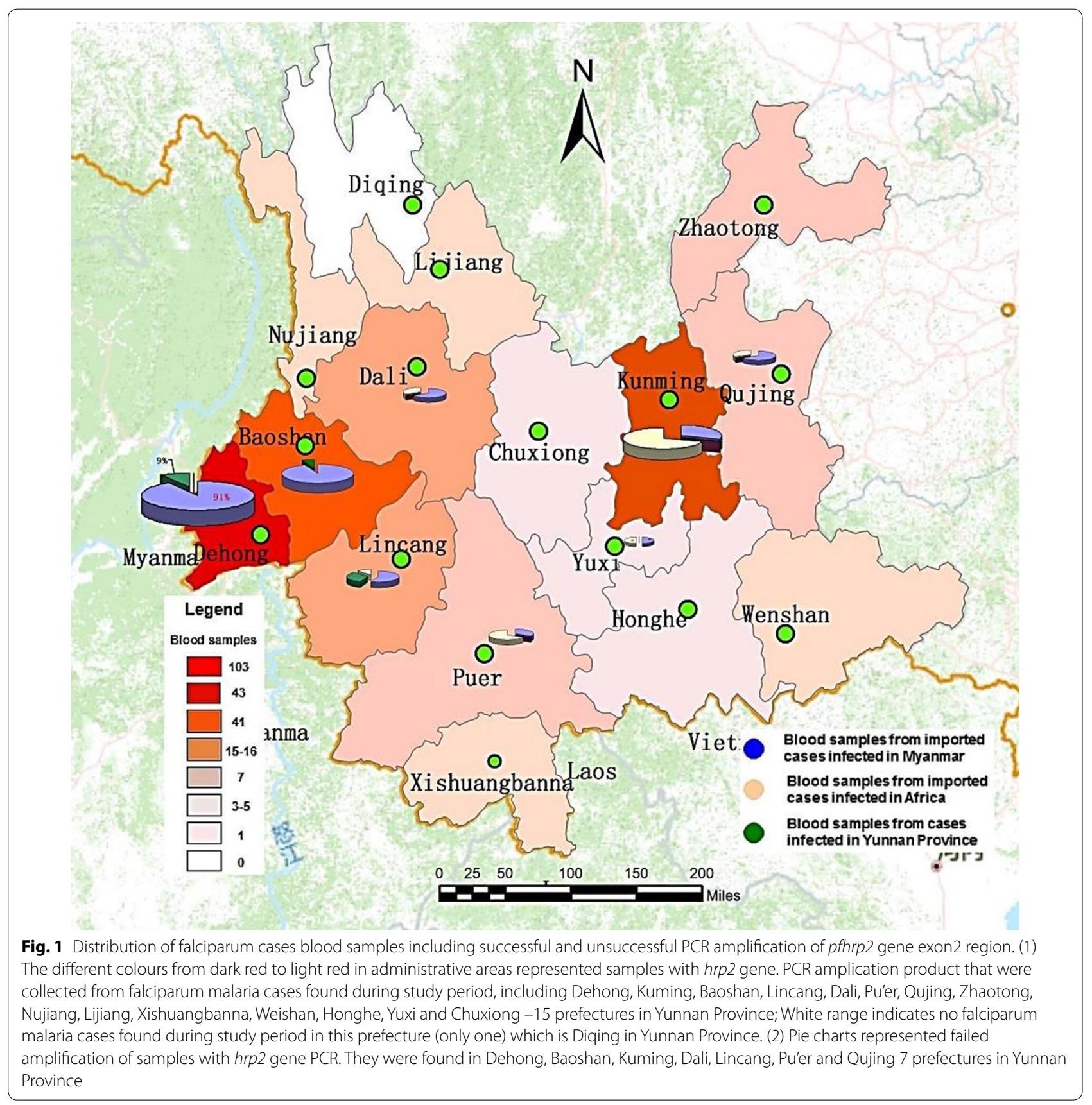


The cases information above collected 259 blood samples was shown in Table 1. The proportions of cases imported from Myanmar infection, imported from African countries infection and Yunnan indigenous infection were $59.5 \%$ (154/259), 36.3\% (94/259) and 4.2\% (11/259), respectively.

Forty-seven blood samples which the pfhrp2 exon2 region was not amplified were collected from 8 prefectures falciparum malaria cases in Yunnan province, including Dehong, Baoshan, Kunming, Lincang, Dali, Puerr, Yuxi, and Qujing. The proportions of these cases imported from Myanmar infection, imported from African countries infection and Yunnan indigenous infection were $63.7 \%$ (29/47), 23.4\% (11/47) and 14.9\% (7/47), respectively. Yunnan indigenous infection cases blood samples with failed amplification of $p f h r p 2$ exon 2 region were only limited to three prefectures including Dehong, Baoshan and Lincang. On the contrary, the blood samples with failed amplification of that gene fragment which were collected from Kunming and Qujing prefectures involved a large number of cases imported from Africa counties infection (Fig. 1).

\section{Polymorphism of DNA sequences}

A total of 250 DNA sequences of the $p f h r p 2$ exon2 region were obtained by sequencing 259 PCR amplification products, with lengths ranging from 345 to $927 \mathrm{bp}$. Polymorphic analyses showed that there were 151 haplotypes, Hap_001-Hap_151, and that PI and He were 0.169 and 0.983 , respectively. There were 87,77 and 10 haplotypes in 146 Myanmar geographical populations, 89 African geographical populations and 15 Yunnan geographical populations which were traced by epidemiological investigation, respectively. The PI and $\mathrm{He}$ of the three geographical populations were 0.167 and $0.974,0.219$ and $0.997,0.249$ and 0.981 , respectively.

Hap_016, with a DNA sequence length of $771 \mathrm{bp}$, was present in the largest proportion of the 151 haplotypes, accounting for $16.0 \%(40 / 250)$. The remaining haplotypes were Hap_004 (7.2\%, 18/250), Hap_014 (6.4\%, 16/250), Hap_008 and Hap_058 (4.0\%, 10/250), Hap_105 (3.2\%, 8/250), and Hap_030 (2.4\%, 6/250) (Fig. 2). Seventeen haplotypes including Hap_005, twelve haplotypes including Hap_017, and twenty-eight haplotypes including Hap_026, accounted for $1.6 \%$ (4/250), 1.2\% (3/250), and $0.8 \%(2 / 250)$, respectively. The others' eighty-three haplotypes with only one sequence had a frequency of $0.4 \%$ $(1 / 250)$.

PCA scatter plots of 151 haplotypes showed that the haplotypes with smallest score $(-12.910)$ (Y: -14.041 , $\mathrm{Z}: 3.889)$ and the largest score $(13.543$ (Y: $-4.160, \mathrm{Z}$ : $34.599)$ in the $X$-axis direction were two sequences from Myanmar geographical isolates. The haplotypes with the smallest score $(-13.685)$ (X: 11.954, Z: 0.804) and the largest score (14.593) (X: 1.744, Z: -2.442) in the Y-axis direction included one Myanmar isolate and one African isolate. Haplotypes with the smallest score $(-12.873)$ (X: 6.167, Y: - 8.421) and the largest score (34.599) (X: 13.543, Y: -4.160$)$ in the $\mathrm{z}$-axis direction were also from two Myanmar isolates.

Eleven high frequency haplotypes, including "Hap_014", “Hap_016", “Hap_105”, “Hap_058”, “Hap_030", “Hap_038”, “Hap_044", "Hap_004", "Hap_008”, "Hap_096", and "Hap_064", with the PCA locations, X: 4.134, Y: 2.598, Z: 1.951; X: - 3.927, Y: 8.212, Z: 2.775; $\mathrm{X}:-6.644, \mathrm{Y}:-8.952, \mathrm{Z}:-2.350 ; \mathrm{X}: 2.480, \mathrm{Y}: 11.215$, $\mathrm{Z}:-3.569$; X: -4.944 , Y: 0.798, Z: 0.178; X: 9.492, Y: $-0.388, \mathrm{Z}:-8.409 ; \mathrm{X}:-0.427, \mathrm{Y}: 0.694, \mathrm{Z}:-0.463$;

Table 1 Information of 259 falciparum malaria cases with their blood samples successful amplified out pfhrp2 gene exon2 fragments

\begin{tabular}{|c|c|c|c|c|c|c|c|}
\hline Years information & 2013 & 2014 & 2015 & 2016 & 2017 & 2018 & Total \\
\hline Number & 62 & 50 & 68 & 26 & 25 & 28 & 259 \\
\hline \multicolumn{8}{|l|}{ 1. $\mathrm{Age}^{\mathrm{a}}$} \\
\hline Maximum & 58 & 56 & 59 & 58 & 57 & 49 & 56 \\
\hline Minimum & 8 & 2 & 10 & 15 & 8 & 1 & 7 \\
\hline Average & 33 & 31 & 33 & 38 & 31 & 33 & 33 \\
\hline \multicolumn{8}{|l|}{ 2. Gender ${ }^{b}$} \\
\hline Male & 56 & 42 & 67 & 26 & 22 & 26 & 239 \\
\hline Female & 6 & 8 & 1 & 0 & 3 & 2 & 20 \\
\hline \multicolumn{8}{|l|}{ 3. Infection source } \\
\hline Myanmar & 36 & 40 & 49 & 14 & 8 & 7 & 154 \\
\hline Africa & 21 & 4 & 19 & 12 & 17 & 21 & 94 \\
\hline Yunnan indigenous & 5 & 6 & 0 & 0 & 0 & 0 & 11 \\
\hline
\end{tabular}

${ }^{a}$ Years old; ${ }^{b}$ Numbers; ${ }^{c}$ dentified by epidemiological investigation 


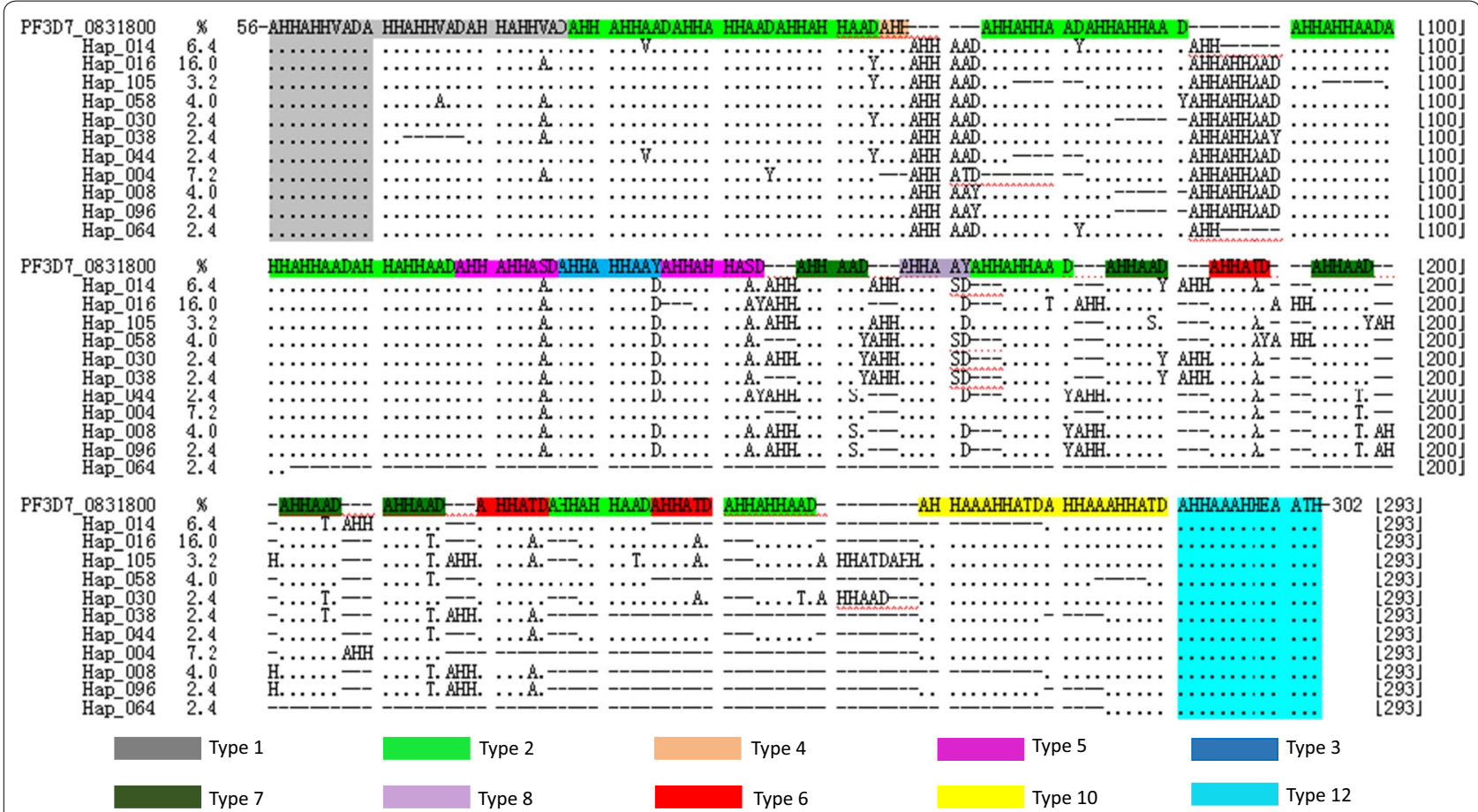

Fig. 2 Alignment mapping of amino acid chains from different haplotypes. The alignment reference sequence was PF3D7_0831800. The alignment region of amino acid chain was from 57th to 301 th aa in pfhrp2 gene exon2 region

$\mathrm{X}:$ 10.719, Y: $-12.883, \mathrm{Z}:-6.025$; X: 8.430, Y: 1.204, Z: 2.151; X: 6.962, Y: 2.430, Z: 0.230; and X: 13.543, Y: -4.160 , Z: 34.599 , respectively, were discrete and nonoverlapping. Also, the haplotype which only composed of the sequences from Myanmar isolates, Africa isolates or Yunnan isolates, did not show any aggregation tendency (Fig. 3).

Following the translation of 250 DNA sequences into amino acid sequences, the longest was 309 aa of haplotype Hap_114, and the shortest was 115 aa of Hap_064 (Fig. 2), with an overall average length of 245 aa $( \pm 26.256)$. Of these, the average amino acid chain lengths of Myanmar population, African population and Yunnan population were $242( \pm 29.163)$ aa, 251 $( \pm 19.750)$ aa and $241( \pm 19.721)$ aa, respectively, and the difference in amino acid chain length among different geographical populations was statistically significant $(F=3.227, P=0.041)$.

\section{Structural characteristics of $P$ fHRP2 peptide chains}

A total of 19 amino acid repeat types were found in 250 amino acid sequences (Table 1). Of these, type 2 (AHHAHHAAD) and type 12 (AHHAAAHHEAATH) repeats occurred in all $(100 \%, 250 / 250)$ the amino acid sequences, with type 12 repeats as the final sequence (Fig. 2). For the initial sequence repetitions of N-terminal, 98.0\% $(245 / 250)$ were type 1 (AHHAHHVAD)
(Fig. 3), and 2.0\% (5/250) were type 2 (AHHAHHAAD). When each amino acid sequence was used to count the repetition types, type 2 repetition repeated the most frequent (12.32 times/sequence), and others occurred as follows: 4.79 times/sequence of type 7, 2.99 times/sequence of type 6, 2.59 times/sequence of type 1, and 1.52 times/ sequence of type 10 (Table 2 ).

The average repetition times for types $1,2,3,4,5,6$, 7, 8, 10, 13 in Myanmar geographical population, Africa geographical population and Yunnan geographical population were not statistically significant $(F=0.032,1.296$, $0.370,0.186,0.540,1.130,0.263,2.282,0.645,3.125$, respectively; $P>0.05)$. Moreover, the three amino acid repetitions of "AHHAHHAAH", "AHHAHHAPD" and "AHHAHHAPH" similar to type 2, the "AHHAHHAPY" similar to type 3, the "AHHAPD" and "AHHAPH" similar to type 7, and the "AHHAPY" similar to type 8 only appeared in the sequences of Myanmar population and African population (Table 2).

\section{RDT testing sensitivity for PfHRP2 peptide chains}

The sensitivity testing of RDTs for PfHRP2 peptide chains based on predictions of type 2 and type 7 amino acid repetition frequencies suggested that the products of the number of $P f H R P 2$ repeat types 2 and 7 (type $2 \times$ type 7 ) were between 52 and 99 in group B accounted for most PfHRP2 peptide chains $(50.0 \%, 125 / 250)$. The shared 


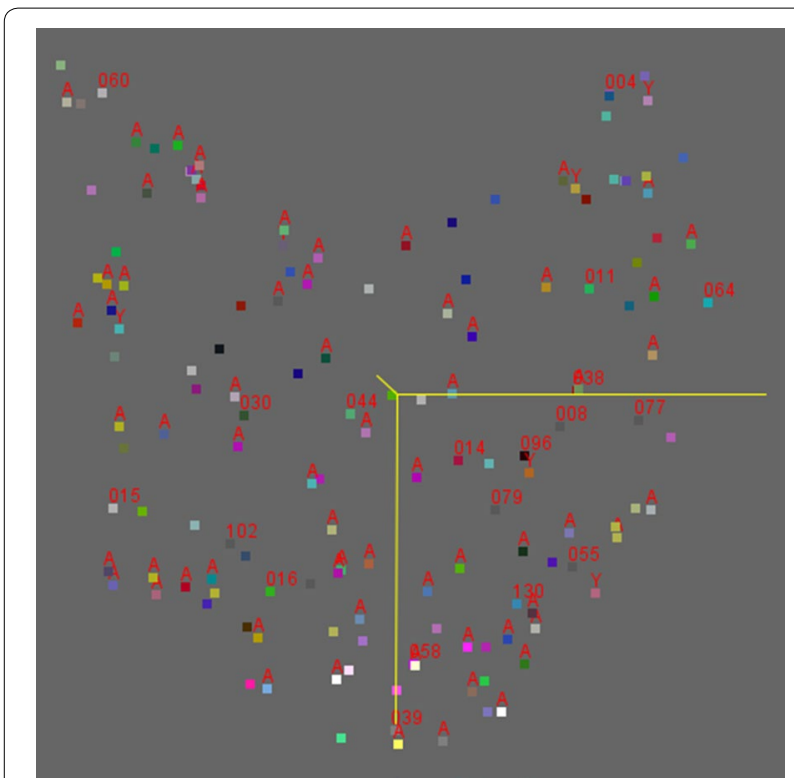

Fig. 3 PCA scatter plots of DNA sequences haplotypes of hrp2 exon2 region from different infection source $P$. falciparum isolates. (1) The horizontal yellow line was the $X$ axis, and vertical yellow line the $Y$ axis, and left inclined yellow line the $Z$ axis. (2) The different color blocks represented haplotypes, in which yellow blocks were these haplotypes with the minimum PCA value and red blocks were those with the maximum PCA value. (3) The number labels on the block were the haplotype names with frequencies greater than $0.8 \%$. A labels block are haplotypes with only sequence of African isolates, and $\mathrm{Y}$ labels block are haplotypes with only sequence of Yunnan Province local isolates, and no labels block are haplotypes with only sequence of Myanmar isolates

advantages in Myanmar, Africa, and Yunnan was also reflected, but the separation plant taxa of group B peptides in Myanmar were lower than African and Yunnan isolates $(t=28.802, P<0.05)$ (Table 3$)$. The product between 100 and 182 had the least proportion of group A PfHRP2 peptide chains $(9.6 \%, 24 / 250)$, and the proportion of group A peptide chains isolated from Myanmar was significantly lower than those from African and Yunnan isolates $(t=12.306, \mathrm{P}<0.05)$ (Table 3). On the contrary, the proportion of group I and group $\mathrm{C}$ peptide chains from Myanmar isolates was significantly higher than those of African $(t=20.562, P<0.05)$ and Yunnan $(t=38.045, P<0.05)$ isolates (Table 3$)$.

\section{Discussion}

pfhrp2 gene (1064 bp) is located in the chromosome 8 telomere area [35], and consists of one non-coding region, one intron area, and one histidine and alanine tandem repeat as dominant in coding regions. The alanine and histidine tandem repeats about $1000 \mathrm{bp}$, and the secretory area at upstream of the coding area 5 - terminal constitutes the exon 2 region (a total of 305 coding amino acids). Due to the instability of the telomeres, the frequent recombination in $p f h r p 2$ gene region is prone to lead to increased mutations and a more complex diversity of amino acid tandem repeats [16, 37-40]. The deletion of pfhrp2 gene exon2 [15] and the protein variation of expressed PfHRP2 not only affect the accuracy of RDTs diagnosis falciparum malaria against $P f \mathrm{HRP} 2$ target protein, but also lead to the potential harm of changing the habits of Plasmodium and even changing the prevalence intensity of malaria [41].

PfHRP2 is not only involved in transforming the toxicity for pigment to poison Plasmodium parasites, but also plays a role in reshaping the structure of the erythrocyte membrane to enhance the immune escape of malaria parasites [42-44].

In this study, the polymorphism of $p f h r p 2$ gene in the 57-301 aa coding region, which is also a dense repeat region of alanine and histidine in the exon2 region, of $P$. falciparum isolates in Yunnan province in the past 6 years was analyzed. Of the 306 blood samples, 250 samples had obtained the target DNA sequence (345$927 \mathrm{bp}$ ), which are similar in length from the geographical isolates in Senegal [21], Nigeria [23], Yemen [29], and Mozambique $[45,46]$. There were 151 haplotypes in the DNA sequence, with a PI of 0.169, which is higher than those in Mali (0.005) and Angola (0.011) [21], and lower than that in Eritrea (0.580) [45]. Furthermore, the haplotype which there was only one DNA sequence accounted for $33.2 \%$ (83/250) of the 250 DNA sequences, which was less than was observed by Deme et al. $(43.3 \%, 29 / 67)$ [21] and Baker et al. $(56.6 \%, 259 / 458)$ [29] in their analyses of mixed samples in Africa. This result suggests that the differentiation of $p f h r p 2$ gene in the sample isolates was greater than that previously reported in African isolates [21, 29], which may be due to the inclusion of complex geographical populations and highly differentiated isolates in the sample. The nucleic acid diversity index (PI) of pfhrp 2 gene from the Yunnan isolates was as high as 0.249 , which is the highest among Myanmar, African and Yunnan groups.

The 250 PfHRP2 peptide chains derived from the DNA sequence were between 115 and 309 aa in length, with an average of $245 \mathrm{aa}$, from total cases isolates. The length of 242 aa from the Myanmar isolates was consistent with the study conducted by Baker et al. [29], but shorter than Haiti's 262 aa, Brazil's 261 aa and Vietnam's 274 aa. This result further enriched the polymorphism of the $p f h r p 2$ gene exon2 region in Southeast Asia. It is interesting to note that for the same infection across the same period, when we compared the pfhrp2 gene exon2 area and DNA sequences, and found that the peptides and amino acids of $p f h r p 2$ with the same chain length as other infection isolates have different sequence structures. A prompt 
Table 2 Amino acid repeat types and number of pfhrp2 gene exon2 region in different geographical isolates from Yunnan Province

\begin{tabular}{|c|c|c|c|c|c|c|c|c|c|c|c|c|}
\hline \multirow[t]{2}{*}{ Repeat types } & \multirow{2}{*}{$\begin{array}{l}\text { Characteristic } \\
\text { repeat sequence }\end{array}$} & \multirow[t]{2}{*}{ Number (\%) } & \multirow[t]{2}{*}{ Mean } & \multicolumn{3}{|c|}{ Myanmar } & \multicolumn{3}{|c|}{ Africa } & \multicolumn{3}{|c|}{ Yunnan indigenous } \\
\hline & & & & Mini & Maxi & Mean & Mini & Maxi & Mean & Mini & Maxi & Mean \\
\hline 1 & AHHAHHVAD & $245(98.0)$ & 2.59 & 1 & 5 & 2.39 & 1 & 6 & 2.35 & 1 & 4 & 2.3 \\
\hline \multirow[t]{4}{*}{2} & AHHAHHAAD & $250(100.0)$ & 12.32 & 1 & 19 & 2.37 & 7 & 16 & 2.31 & 11 & 16 & 13.6 \\
\hline & AHHAHHAAH & $5(2.0)$ & 0.04 & 1 & 3 & 2.33 & 1 & 3 & 2.0 & 0 & 0 & 0 \\
\hline & AHHAHHAPD & $14(5.6)$ & 0.18 & 1 & 3 & 2.0 & 1 & 9 & 3.80 & 0 & 0 & 0 \\
\hline & AHHAHHAPH & $9(3.6)$ & 0.18 & 5 & 5 & 5.0 & 1 & 10 & 4.88 & 0 & 0 & 0 \\
\hline \multirow[t]{2}{*}{3} & AHHAHHAAY & $235(94.0)$ & 1.33 & 1 & 5 & 1.36 & 1 & 2 & 1.37 & 1 & 2 & 1.2 \\
\hline & AHHAHHAPY & $5(2.0)$ & 0.02 & 1 & 1 & 1.0 & 1 & 1 & 1.0 & 0 & 0 & 0 \\
\hline 4 & $\mathrm{AHH}$ & $116(46.4)$ & 1.05 & 1 & 34 & 2.37 & 1 & 3 & 1.6 & 1 & 2 & 1.67 \\
\hline 5 & AHHAHHASD & $166(66.4)$ & 0.80 & 1 & 6 & 1.16 & 1 & 5 & 1.33 & 1 & 2 & 1.17 \\
\hline 6 & AHHATD & $246(98.4)$ & 2.99 & 1 & 7 & 2.86 & 1 & 7 & 3.19 & 2 & 4 & 2.8 \\
\hline \multirow[t]{3}{*}{7} & AHHAAD & $246(98.4)$ & 4.79 & 1 & 11 & 4.45 & 1 & 11 & 4.35 & 1 & 6 & 3.9 \\
\hline & AHHAPD & $15(6.0)$ & 0.12 & 1 & 3 & 1.22 & 2 & 4 & 3.17 & 0 & 0 & 0 \\
\hline & AHHAPH & $6(2.4)$ & 0.06 & 1 & 3 & 2.0 & 2 & 3 & 2.75 & 0 & 0 & 0 \\
\hline \multirow[t]{2}{*}{8} & AHHAAY & $231(92.4)$ & 1.11 & 1 & 2 & 1.15 & 1 & 2 & 1.1 & 1 & 3 & 1.4 \\
\hline & AHHAPY & $5(2.0)$ & 0.04 & 1 & 3 & 2.0 & 1 & 3 & 1.67 & 0 & 0 & 0 \\
\hline 10 & AHHAAAHHATD & $228(91.2)$ & 1.52 & 1 & 4 & 1.63 & 1 & 3 & 1.78 & 1 & 2 & 1.67 \\
\hline 12 & AHHAAAHHEAATH & $250(100.0)$ & 1.00 & 1 & 1 & 1 & 1 & 1 & 1 & 1 & 1 & 1 \\
\hline 13 & AHHASD & $33(13.2)$ & 0.14 & 1 & 1 & 1 & 1 & 2 & 1.33 & 1 & 1 & 1 \\
\hline 14 & AHHAHHATD & $20(8.0)$ & 0.08 & 1 & 1 & 1 & 1 & 1 & 1 & 1 & 1 & 1 \\
\hline
\end{tabular}

investigation of $p f h r p 2$ gene mutation and gene exon2 region diversity may have potential gene traceability between different $P$. falciparum isolates.

Regarding the PfHRP2 peptide amino acid repeat feature recognition, all 250 peptide chains showed 19 kinds of repeats, including type 1 , type 2 and its three variation types, type 3 and its one variation type, type 4 , type 5 , type 6 , type 7 and its two variation types, type 8 and its one variation type 10, type 12 and type 13 (Table 1 ). The repeats of types 9 and type 11 was not observed in this study. These repetitive features differed from those 13 types obtained from India isolates by Kumar et al. [18, 47], 12 repeating characteristics from Senegal isolates by Deme et al. [21], 14 repeating patterns from mixed isolates collecting from many countries by Baker et al. [29], and 39 repeating patterns from Kenya isolates by Nderu et al. [30]. However, in all these studies, amino acid residues repetition of types $1-8$, type 10 and type 12 were found. The pattern starting with type 1 repetition and ending with type 12 repetitions were relatively fixed, and they were found in all peptide chains. However, further comparison with different studies showed that the identified amino acid repeat types of the PfHRP2 peptide chain must be in accordance with the stable identification criteria, especially when the amino acid repeat types in PfHRP2 exon2 region were used for predicting RDT reactivity for the PfHRP2 peptide chain. Although the amino acid repeat sequence of $P f \mathrm{HRP} 2$ peptide chain were summarized as type 1 , type 2 , type 3 , type 4 , type 5 , type 6 , type 7 , type 8 , type 10 , type 12 , type 13 , type 14 and other variants $[18,20,30]$, the recognition and counting of repeat types can only be done manually. Therefore, potential counting differences might exist caused by different counting strategies. For example, type 2 (AHHAHHAAD) was counted as a linkage between type $4(\mathrm{AHH})$ and type 7 (AHHAAD), while type 14 (AHHAHHATD) was counted as a linkage between type $4(\mathrm{AHH})$ and type 6 (AHHATD), which resulted in trading off and taking turns of type 2 , type 4 , type 6 , and type 7 . Due to the complex recognition principle of "long rather than short" in this study, the differences may occur in the recognition and counting of type 2, type 7 and type 4 repetitions compared with those of Yang et al. [27] and Li et al. [48]. For the detection of blood samples from falciparum malaria cases in Yunnan province, the average number of repetitions of type 7 and type 4 in this study were 4.8 times and 1.0 time, respectively, while Yang's type 7 was 15.6 times, with no type 4 repeat characteristics [27], showing a significant difference.

Studies have demonstrated that antigen variation is a risk factor for the unstable quality of falciparum malaria diagnosed by RDTs based on immune response [26, 49], and the epitope region of the PfHRP2 peptide chain is thought to be mainly confined to its central region [50]. 


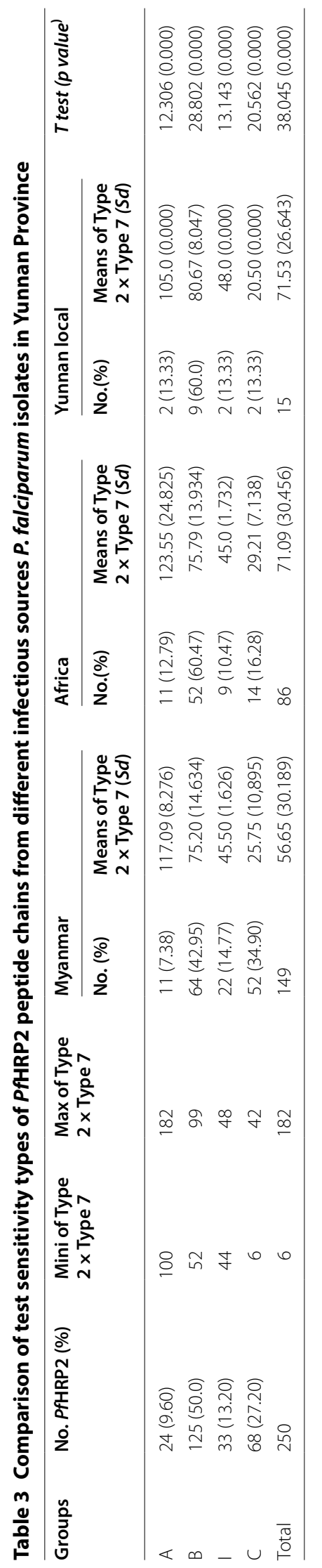


Therefore, rapid prediction of RDTs testing sensitivity for PfHRP2 peptide chain by type 2 repeat times and type 7 repeat times have become a trend [18, 20, 26, 29, 30]. Studies conducted by Kumar et al. [18] and Wurtz et al. [26] found that when the products of type 2 and type 7 repeat times are $<43$ (group $C$ chain), RDTs will find it difficult to detect the presence of this PfHRP2 chain. Fortunately, the PfHRP2 peptide chain belonging to group $\mathrm{C}$ was not the dominant species in the current study samples. In this study, the PfHRP2 peptide chain of group C only accounted for $27.3 \%(68 / 250)$, but it was still higher than that of the samples from Senegal $(7.4 \%, 9 / 122)$ [26] and in Kenya $(9.8 \%, 24 / 244)$ [30]. In contrast, the dominant species were PfHRP2 peptide chains belonging to group B, accounting for $50.0 \%$ (125/250), which was lower than $71.3 \%(87 / 122)$ [26] and $75.8 \%(185 / 244)$ [30] obtained from previous studies. This suggested that there may be more RDT detection failures than those for African isolate alone in this study, which was mixed with many Myanmar isolates (59.6\%, 149/250). Unfortunately, matched pair study between falciparum malaria diagnosed using RDT in Yunnan province and the polymorphic structure of PfHRP2 peptide chain have not been implemented. Therefore, it is not possible to infer whether PfHRP2 peptide chain variation affects falciparum malaria diagnosis in Yunnan province.

In this study, pfhrp 2 gene was not amplified in $15.36 \%$ $(47 / 306)$ of the samples when extracting $P$. falciparum genomic DNA was confirmed to be normal from these samples. Still, the author could not ensure that the $P$. falciparum isolates in these samples can be considered entire deficiency of $p f h r p 2$ gene. First, $p f h r p 2$ gene deletion was not verified through Cheng's method [51]. Second, although the nested PCR method was used in this study to amplify pfhrp 2 gene with higher amplification efficiency than Kumar et al. [18] and Baker et al. [20], the amplified fragment only covered the region from the intron to 248 bp downstream of $p f h r p 2$ gene, and the sensitivity to confirm pfhrp2 (gene) deletion may not have been high enough. Parr et al. [52] and Trouvay et al. [53] adopted whole genome sequencing, while Gupta et al. [46] and Ranadive et al. [54] amplified the region to form the upstream and downstream of $p f h r p 2$ gene extension [51], while the phenomenon of pfhrp 2 gene deletion was not found or rarely found. However, more phenomenon of $p f h r p 2$ gene deletion were found only in amplifying exon2 region alone $[20,36,55]$, which suggests that analysis of the exon2 region of pfhrp 2 gene alone may be less sensitive than whole-genome or upstream and downstream extension assays for confirmation of pfhrp 2 gene entire deletion. Third, the failure to amplify the $p f h r p 2$ gene above 47 samples does not rule out the effect of low Plasmodium density. Gupta et al. indicated that the analysis on $p f h r p 2$ gene deletion was unreliable when Plasmodium density is only $3 \sim 330$ parasites/ $\mu l$. Therefore, the study conducted by Beshir et al. excluded samples with Plasmodium densities $<5$ parasites/ $\mu$ l during validation of $p f h r p 2$ gene deletion. In conclusion, the certification of $p f h r p 2$ gene entire deletion must be rigorous, as the WHO requires that programme must adjust their RDTs product when the proportion of $p f h r p 2$ gene entire deletion of $P$. falciparum achieve to $5 \%$ in a population within an area [56].

This study comprehensively analysed the $p f h r p 2$ gene polymorphism from falciparum malaria cases isolates from January 2013 to December 2018 in Yunnan province. The current $p f h r p 2$ gene polymorphism situation from falciparum malaria case isolates in Yunnan province was reflected due to good continuity and systemic characteristics of these samples. The results of the study will be the basis for further verification of $p f h r p 2$ gene entire deletion and screening of optimal epitopes of PfHRP2 peptide chain. However, this study include several limitations: (1) due to the inability to determine the Plasmodium density in some blood samples, the effect of low protozoan density on the confirmation of $p f h r p 2$ gene deletion cannot be ruled out; (2) polymorphic and deletion of pfhrp 3 gene, which are considered as early signs of $p f h r p 2$ gene deletion [15], were not conducted due to limited human resources; and (3) whether the PfHRP2 peptide chains exists or not in blood samples was not examined in parallel with RDT products in the study.

The study conducted by Watson et al. indicated that low prevalence of malaria and the high frequency for treatment could increase the risk for inappropriate use of antimalarial drugs because malaria might be misdiagnosed by RDTs, which will also lead to transitionally screening on pfhrp2-deficient plasmodium [57]. Currently, there was very low prevalence of malaria and high frequency of malaria-associated medical treatment in China. However, China was not a part of the WHO's global RDT quality monitoring network, and the systematic quality tracking of RDT products were not conducted. Therefore, whether the use of RDTs will accelerate screening for pfhrp2deficient Plasmodium deserves attention. Further rapid verification of the entire deletion of $p f h r p 2$ gene from $P$. falciparum in China deserve higher priority. Fortunately, a more sensitive and specific sequencing analysis method for $p f h r p 2$ gene deletion has developed.

\section{Conclusion}

In conclusion, this study firstly, provides the pfhrp 2 gene diversity information of isolates from falciparum malaria cases diagnosed and reported by Yunnan Province, China. Although the presence of $p f h r p 2$ gene entire deletion is uncertain, the results are a general 
reflection of the presence of pfhrp2 gene polymorphism in Yunnan Province since the study samples are from official cases reported over the years. Therefore, it is necessary that the effectiveness and applicability of RDTs in diagnosis falciparum malaria in Yunnan province should be evaluated in time and it is important that the pfhrp 2 gene-deficient $P$. falciparum isolates should not be excessively screened by blindly extending the use of RDTs.

\section{Acknowledgements}

We appreciate the support from the Centers for Disease Control and Prevention in states/cities and counties such as Dehong, Baoshan, Kunming, Pu'er, Lincang, Dali, Nujiang, Lijiang, Xishuangbanna, Yuxi, Chuxiong, Honghe, Zhaotong, Diqing, Qujing, and Wenshan.

\section{Authors' contributions}

YD was responsible for the coordination of all project, study design, statistics and analysis of the data, and wrote the manuscript; SL carried out the gene testing; YD, YX, MC performed the collection blood samples and microscopy examination; $Y L$ administered the gene testing, and $J X, X J$ guided making the geographical map. All authors read and approved the final manuscript.

\section{Funding}

This study was supported by National Science Foundation, China (Nos. $81220108019,81660559,81960579) ;$ and the Youth Project of Yunnan Province Basic Research Program, China (Nos. 2017FD007, 2017FD190).

\section{Availability of data and materials}

Not applicable.

\section{Ethics approval and consent to participate}

The study was approved by Yunnan Institute of Parasitic Diseases and by the Ethical Committee. Genetic testing experiment, etc. were performed on stored blood samples obtained as part of routine diagnostic work-up patients with fever suspected of malaria. Although the absence of risk and the anonymous data processing are ensured among the study, consent from potential malaria patients need to be obtained during collecting blood samples. Demographic, clinical and epidemiological information of each fever patient will be collected. Database access will be restricted by password, and Yunnan Institute Parasitic Diseases will not allow retrieving and saving the personal identification information into the project database. It is committed not to provide information about the patient to any person unrelated to the study.

\section{Consent for publication}

All authors provided their consent for the publication of this report.

\section{Competing interests}

The authors declare that they have no competing interests.

\section{Author details}

${ }^{1}$ Yunnan Institute of Parasitic Diseases Control, Yunnan Provincial Key Laboratory, Yunnan Centre of Malaria Research, Academician Workstation of Professor Jin Ningyi, Pu'er 665000, China. ${ }^{2}$ School of Basic Medical Sciences, Dali University, Dali 667000, China. ${ }^{3}$ National Institute of Parasitic Diseases, Chinese Center for Disease Control and Prevention, Shanghai 200025, China.

Received: 12 July 2019 Accepted: 21 December 2019

Published online: 30 December 2019

\section{References}

1. Zhang L, Zhou SS, Feng J, Fang W, Xia ZG. Malaria situation in People' Republic of China in 2014. Zhongguo Ji Sheng Chong Xue Yu Ji Sheng Chong Bing Za Zhi. 2015;33:319-26 (in Chinese)
2. Zhou XN, Zhang SS, Xu JF, Xia ZG, Wang RB, Qian YJ. Risk assessment for malaria elimination in P R China. Zhongguo Ji Sheng Chong Xue Yu Ji Sheng Chong Bing Za Zhi. 2014;32:414-8 (in Chinese).

3. Dong Y, Sun AM, Chen MN, XU YC, Mao XH, Deng Y. Polymorphism analysis of the block 5 region in merozoite surface protein-1 gene of imported and local Plasmodium vivax in Yunnan Province. Zhongguo Ji Sheng Chong Xue Yu Ji Sheng Chong Bing Za Zhi. 2017;35:1-7 (in Chinese).

4. Luo ZX, Deng R, Wang X. Monitoring on import cases of malaria and vector species at Menglian port. Chinese J Frontier Health Quarantine. 2011; 34:233-7. http://xueshu.baidu.com/usercenter/paper/show?paper id=5a4cd054199914a60a6613155628cc61\&site=xueshu_se (in Chinese).

5. Zhang JW, Jiang JY, Zeng XC, Zheng YT, Zhou HN. [Study of ecological habits of important malaria vectors in epidemic prone regions of malaria in Yunnan Province, China. Chinese J Vector Biol Control. 2015;26:47-54 (in Chinese)

6. Dong Y, Mao XH, Chen MN, Deng Y, Wang J, Xu YC. Quality analysis of laboratory malaria diagnosis in Yunnan Province during 2012-2014. Zhongguo Ji Sheng Chong Xue Yu Ji Sheng Chong Bing Za Zhi. 2015;33:191-5 (in Chinese)

7. Zhu YJ, Chen MN, Xu YC, Mao XH, Deng Y, Dong Y. Polymorphism of 72-75 coding sequence within exon2 region of Pfcrt in Yunnan Province. Zhongguo Ji Sheng Chong Xue Yu Ji Sheng Chong Bing Za Zhi. 2016:34:227-34 (in Chinese)

8. Liu H, Kang KR, Li CF, Xion XC, Nie RH, Li GS, et al. Effective evaluation of Wonfo rapid diagnostic cassette for Plasmodium falciparum. Parasit Infect Dis. 2008;6:224-5. http://en.cnki.com.cn/Article_en/CJFDTotal-SJCB2 00804019.htm (in Chinese).

9. Xu YC, Chen MN, Mao XH, Deng Y, Sun AM, Dong Y. Laboratory diagnosis of Plasmodium ovale in Yunnan Province. J Pathog Biol. 2016;1 1:541-4. http://www.doc88.com/p-1806347289664.html (in Chinese).

10. Dong Y, Chen MN, Xu YC. A systematic review and meta-analysis: The accuracy of rapid diagnostic tests versus microscopy to detect malaria. J Pathog Biol. 2016;11:353-8. http://xueshu.baidu.com/usercenter/paper /show?paperid =5c67b61957f09d592e4e1ed5361053c7\&site=xuesh U_se\&hitarticle $=1$ (in Chinese).

11. WHO. Protocol for estimating the prevalence of pfhrp2/pfhrp3 gene deletions among symptomatic falciparum patients with false-negative RDT results. Geneva: World Health Organization; 2018.

12. Heutmekers M, Gillet P, Cnops L, Bottieau E, Van Esbroeck M, Maltha J, et al. Evaluation of the malaria rapid diagnostic test SDFK90: detection of both PfHRP2 and Pf-pLDH. Malar J. 2012;11:359.

13. Kemp DJ, Thompson JK, Walliker D, Corcoran LM. Molecular karyotype of Plasmodium falciparum: conserved linkage groups and expendable histidine-rich protein genes. Proc Natl Acad Sci USA. 1987;84:7672-6.

14. Pologe $L G$, Ravetch JV. Large deletions result from breakage and healing of P. falciparum chromosomes. Cell. 1988:55:869-74.

15. Gamboa D, Ho MF, Bendezu J, Torres K, Chiodini PL, Barnwell JW, et al. A large proportion of $P$. falciparum isolates in the Amazon region of Peru lack pfhrp2 and pfhrp3: implications for malaria rapid diagnostic tests. PLoS One. 2010;5:e8091.

16. Akinyi S, Hayden T, Gamboa D, Torres K, Bendezu J, Abdallah JF, et al. Multiple genetic origins of histidine-rich protein 2 gene deletion in Plasmodium falciparum parasites from Peru. Sci Rep. 2013;3:2797.

17. Koita OA, Doumbo OK, Ouattara A, Tall LK, Konaré A, Diakité M, et al. False-negative rapid diagnostic tests for malaria and deletion of the histidine-rich repeat region of the hrp2 gene. Am J Trop Med Hyg. 2012:86:194-8.

18. Kumar N, Singh JP, Pande V, Mishra N, Srivastava B, Kapoor R, et al. Genetic variation in histidine rich proteins among Indian Plasmodium falciparum population: possible cause of variable sensitivity of malaria rapid diagnostic tests. Malar J. 2012;11:298.

19. Kumar N, Pande V, Bhatt RM, Shah NK, Mishra N, Srivastava B, et al. Genetic deletion of HRP2 and HRP3 in Indian Plasmodium falciparum population and false negative malaria rapid diagnostic test. Acta Trop. 2013;125:119-21.

20. Baker J, McCarthy J, Gatton M, Kyle DE, Belizario V, Luchavez J, et al. Genetic diversity of Plasmodium falciparum histidine-rich protein 2 (PfHRP2) and its effect on the performance of PfHRP2-based rapid diagnostic tests. J Infect Dis. 2005; 192:870-7. 
21. Deme AB, Park DJ, Bei AK, Sarr O, Badiane AS, Gueye Pel H, et al. Analysis of pfhrp2 genetic diversity in Senegal and implication for use of rapid diagnostic tests. Malar J. 2014;13:34.

22. Houzé S, Hubert V, Le Pessec G, Le Bras J, Clain J. Combined deletions of pfhrp2 and pfhrp3 genes result in Plasmodium falciparum malaria falsenegative rapid diagnostic test. J Clin Microbiol. 2011;49:2694-6.

23. Atroosh WM, Al-Mekhlafi HM, Al-Jasari A, Sady H, Al-Delaimy AK, Nasr NA, et al. Genetic variation of pfhrp2 in Plasmodium falciparum isolates from Yemen and the performance of HRP2-based malaria rapid diagnostic test. Parasit Vectors. 2015;8:388.

24. Abdallah JF, Okoth SA, Fontecha GA, Torres RE, Banegas El, Matute ML, et al. Prevalence of pfhrp2 and pfhrp3 gene deletions in Puerto Lempira, Honduras. Malar J. 2015;14:19.

25. Amoah LE, Abankwa J, Oppong A. Plasmodium falciparum histidine rich protein-2 diversity and the implications for PfHRP 2: based malaria rapid diagnostic tests in Ghana. Malar J. 2016;15:101

26. Wurtz N, Fall B, Bui K, Pascual A, Fall M, Camara C, et al. Pfhrp2 and pfhrp3 polymorphisms in Plasmodium falciparum isolates from Dakar, Senegal: impact on rapid malaria diagnostic tests. Malar J. 2013;12:34.

27. Yang YC, Zhang J, Wang GZ, Bo SY, Zhang Y, Xin XF. Polymorphism analysis of Plasmodium falciparum histidine-rich protein Iland III. Zhongguo Ji Sheng Chong Xue Yu Ji Sheng Chong Bing Za Zhi. 2014;32:373-6 (in Chinese)

28. Ying D, Ai-Ming S, Meng-Ni C, Yan-Chun X, Xiang-Hua M, Yan D, et al. Analysis of polymorphism of Pfhrp2 gene in Plasmodium falciparum from falciparum malaria patients in Yunnan Province. Zhongguo Xue Xi Chong Bing Fang Zhi Za Zhi. 2016;28:411-7 (in Chinese).

29. Baker J, Ho MF, Pelecanos A, Gatton M, Chen N, Abdullah S, et al. Global sequence variation in the histidine-rich proteins 2 and 3 of Plasmodium falciparum: implications for the performance of malaria rapid diagnostic tests. Malar J. 2010:9:129.

30. Nderu D, Kimani F, Thiong'o K, Karanja E, Akinyi M, Too E, et al. Plasmodium falciparum histidine-rich protein (PAHRP2 and 3) diversity in Western and Coastal Kenya. Sci Rep. 2019;9:1709.

31. Department of Health of China. Diagnostic criteria for malaria (WS 2592006). People's Republic of China health industry standard. 2006. https:// wenku.baidu.com/view/a95f3dabdd3383c4bb4cd246.html (in Chinese).

32. Zhu YJ,Deng Y, Mao XH, Wang J, Chen MN, Dong Y. Analysis of the homology of the 18S sRNA gene of Plasmodium isolates from different sources of infection. Chinese J Parasitol Parasitic Dis. 2014;9:331-4. http://xuesh u.baidu.com/usercenter/paper/show?paperid=9e0e19890cb6205f35db 6360d74b24a1\&site $=x$ ueshu se\&hitarticle $=1$ (in Chinese).

33. Dong Y, Sun AM, Deng Y, Chen MN, Xu YC, Mao XH. Analysis on comutation of chloroquine-resistant gene and artemisinin-resistant gene in Plasmodium falciparum in Yunnan Province. Zhongguo Ji Sheng Chong Xue Yu Ji Sheng Chong Bing Za Zhi. 2017;35:202-9. http://xueshu.baidu .com/usercenter/paper/show?paperid=8c9625557a4f29e1 be13fb5d6 db2b281\&site=xueshu_se (in Chinese).

34. Zhang L, Feng J, Zhang SS, Xia ZG, Zhou SS. Malaria situation in the People's Republic of China in 2015. Zhongguo Ji Sheng Chong Xue Yu Ji Sheng Chong Bing Za Zhi. 2016;34:477-81 (in Chinese).

35. Dong Y, Deng Y, Xu YC, Chen MN, Mao XH, Sun AM, et al. Analysis of genes associated with antifolate drug resistance in Plasmodium vivax from different infection sources. Zhongguo Ji Sheng Chong Xue Yu Ji Sheng Chong Bing Za Zhi. 2018;36:203-11. http://xueshu.baidu.com/ usercenter/paper/show?paperid=9e0e19890cb6205f35db6360d74b24 a $1 \&$ site $=x u e s h u \_s e \& h i t a r t i c l e=1$ (in Chinese).

36. Dong Y, Wang J, Sun AM, Deng Y, Chen MN, Xu YC, et al. Genetic association between the Pfk13 gene mutation and artemisinin resistance phenotype in Plasmodium falciparum isolates from Yunnan Province, China. Malar J. 2018;17:478.

37. Figueiredo LM, Freitas-Junior LH, Bottius E, Olivo-Marin JC, Scherf A. A central role for Plasmodium falciparum subtelomeric regions in spatial positioning and telomere length regulation. EMBO J. 2002;21:815-24.

38. Volkman SK, Hartl DL, Wirth DF, Nielsen KM, Choi M, Batalov S, et al. Excess polymorphisms in genes for membrane proteins in Plasmodium falciparum. Science. 2002;298:216-8.

39. Ribacke U, Mok BW, Wirta V, Normark J, Lundeberg J, Kironde F, et al. Genome wide gene amplifications and deletions in Plasmodium falciparum. Mol Biochem Parasitol. 2007;155:33-44.
40. Figueiredo L, Scherf A. Plasmodium telomeres and telomerase: the usual actors in an unusual scenario. Chromosome Res. 2005;13:517-24.

41. Babiker HA, Walliker D. Current views on the population structure of Plasmodium falciparum: implications for control. Parasitol Today. 1997;13:262-7.

42. Choi CY, Cerda JF, Chu HA, Babcock GT, Marletta MA. Spectroscopic characterization of the heme-binding sites in Plasmodium falciparum histidine-rich protein 2. Biochemistry. 1999;38:1616-24.

43. Benedetti CE, Kobarg J, Pertinhez TA, Gatti RM, de Souza ON, Spisni A, et al. Plasmodium falciparum histidine-rich protein II binds to actin, phosphatidylinositol 4,5-bisphosphate and erythrocyte ghosts in a $\mathrm{pH}$ dependent manner and undergoes coil-to-helix transitions in anionic micelles. Mol Biochem Parasitol. 2003;128:157-66.

44. Bosshart $\mathrm{H}$, Heinzelmann M. Endotoxin-neutralizing effects of histidinerich peptides. FEBS Lett. 2003;553:135-40.

45. Sepúlveda N, Phelan J, Diez-Benavente E, Campino S, Clark TG, Hopkins $\mathrm{H}$, et al. Global analysis of Plasmodium falciparum histidine-rich protein-2 (pfhrp2) and pfhrp3 gene deletions using whole-genome sequencing data and meta-analysis. Infect Genet Evol. 2018;62:211-9.

46. Gupta H, Matambisso G, Galatas B, Cisteró P, Nhamussua L, Simone W, et al. Molecular surveillance of pfhrp2 and pfhrp3 deletions in Plasmodium falciparum isolates from Mozambique. Malar J. 2017;16:416.

47. Kumar Bharti P, Singh Chandel H, Krishna S, Nema S, Ahmad A, Udhayakumar $V$, et al. Sequence variation in Plasmodium falciparum histidine rich proteins 2 and 3 in Indian isolates implications for malaria rapid diagnostic test performance. Sci Rep. 2017;7:1308.

48. Li P, Xing H, Zhao Z, Yang Z, Cao Y, Li W, et al. Genetic diversity of Plasmodium falciparum histidine-rich protein 2 in the China-Myanmar border area. Acta Trop. 2015;152:26-31.

49. Beshir KB, Sepúlveda N, Bharmal J, Robinson A, Mwanguzi J, Busula $\mathrm{AO}$, et al. Plasmodium falciparum parasites with histidine-rich protein 2 (pfhrp2) and pfhrp3 gene deletions in two endemic regions of Kenya. Sci Rep. 2017;7:14718.

50. Lee N, Gatton ML, Pelecanos A, Bubb M, Gonzalez I, Bell D, et al. Identification of optimal epitopes for Plasmodium falciparum rapid diagnostic tests that target histidine-rich proteins 2 and 3. J Clin Microbiol. 2012;50:1397-405.

51. Cheng Q, Gatton ML, Barnwell J, Chiodini P, McCarthy J, Bell D, et al. Plasmodium falciparum parasites lacking histidine-rich protein 2 and 3: a review and recommendations for accurate reporting. Malar J. 2014;13:283.

52. Parr JB, Verity R, Doctor SM, Janko M, Carey-Ewend K, Turman BJ, et al. Pfhrp2-deleted Plasmodium falciparum parasites in the Democratic Republic of the Congo: a national cross-sectional survey. J Infect Dis. 2017;216:36-44.

53. Trouvay M, Palazon G, Berger F, Volney B, Blanchet D, Faway E, et al. High performance of histidine-rich protein 2 based rapid diagnostic tests in French Guiana are explained by the absence of pfhrp2 gene deletion in P. falciparum. PLoS One. 2013;8:e74269.

54. Ranadive N, Kunene S, Darteh S, Ntshalintshali N, Nhlabathi N, Dlamini N, et al. Limitations of rapid diagnostic testing in patients with suspected malaria A diagnostic accuracy evaluation from Swaziland, a low-epidemical country aiming for malaria elimination. Clin Infect Dis. 2017:64:1221-7.

55. Menegon M, L'Episcopia M, Nurahmed AM, Talha AA, Nour BYM, Severini C, et al. Identification of Plasmodium falciparum isolates lacking histidinerich protein 2 and 3 in Eritrea. Infect Genet Evol. 2017;55:131-4.

56. WHO. P. falciparum hrp2/3 gene deletions. Malaria Policy Advisory Committee Meetion Geneva: World Health Organization; 2016. http://www. who.int/malaria/mpac/mpac-sept2016-hrp2-consultation-short-repor t-session7.pdf?ua=1.

57. Watson OJ, Slater HC, Verity R, Parr JB, Mwandagalirwa MK, Tshefu A, et al. Modelling the drivers of the spread of Plasmodium falciparum hrp2 gene deletions in sub-Saharan Africa. Elife. 2017;6:e25008.

\section{Publisher's Note}

Springer Nature remains neutral with regard to jurisdictional claims in published maps and institutional affiliations. 